\title{
Detection of Adenovirus Infection Among Children With Acute Respiratory Disease During 2010-2012 in Shiraz, Iran
}

\author{
Afagh Moattari ${ }^{1, *}$; Amir Emami ${ }^{1}$; Neda Pirbonyeh ${ }^{1}$; Ramin Yaghoobi ${ }^{2}$ \\ ${ }_{1}^{1}$ Bacteriology and Virology Department, Shiraz Medical School, Shiraz University of Medical Sciences, Shiraz, IR Iran \\ ${ }^{2}$ Shiraz Transplant Research Center, Namazi Hospital, Shiraz University of Medical Sciences, Shiraz, IR Iran \\ ${ }^{*}$ Corresponding author: Afagh Moattari, Bacteriology and Virology Department, Shiraz Medical School, Shiraz University of Medical Sciences, Shiraz, IR Iran. Tel: +98-9173136844, Fax: \\ +98-7112304356, E-mail:moattaria@yahoo.com
}

Received: November 2, 2013; Revised: December 4, 2013; Accepted: January 15, 2014

\begin{abstract}
Background: Acute viral respiratory infection (ARVI) is a common cause of morbidity and mortality especially in pediatric patients. Among important respiratory pathogens, adenovirus is a most prevalent cause of upper and lower respiratory tract infection.

Objectives: The aim of the present study was to determine the prevalence of adenovirus infection in pediatric patients with respiratory symptoms.

Patients and Methods: This cross-sectional study was carried out from November 2010 to February 2012. An in-house nested-PCR was used to detect adenovirus in nasopharyngeal swabs from 328 children, aged 19 years or younger, with acute upper respiratory tract symptoms referred to the hospitals affiliated with Shiraz University of Medical Sciences.

Results: Adenovirus was detected in $22 \%$ of 328 nasopharyngeal swabs and the highest rate of hospitalization (74\%) due to ARVI associated with fever, cough and muscular ache was found in children older than five years.

Conclusions: The results of this study showed that acute respiratory infection due to adenovirus in Shiraz mostly occur during November to February. In contrast to other studies, adenovirus infection was more prevalent in children aged older than 5 years.

Keywords:Adenoviridae Infections; Respiratory Tract Infection; Pediatrics; Iran
\end{abstract}

\section{Background}

Acute respiratory tract infections (ARTI) are regarded as important causes of morbidity and mortality in pediatric patients. This refers to both outpatient visits and 20$40 \%$ of hospitalized patients $(1,2)$. The significant impact of these infections on developing countries is based on the fact that nearly $50 \%$ of pediatric consultations are related to the respiratory tract infection (RTI) (3). The world health organization (WHO) ranks the lower RTIs as the leading cause of disease worldwide, which accounts for 4 million deaths per year $(2,4)$. RTI can be life-threatening depending on the causative agent and host condition. A high incidence of RTI in children is due to increasing exposure of young children to siblings and friends with RTI, childcare centers, and environmental factors. Additionally, susceptibility to ARTI may be due to inherited disorders of the immune system, which are responsible for $45-60 \%$ of all acute respiratory diseases in infants and young children $(2,3)$. Most of these infections are caused by respiratory syncytial virus (RSV), influenza virus A or B (FluV), parainfluenza virus (PIV), rhinovirus (RV), and human adenovirus (HAdV). Several recently discovered viruses such as human metapneumovirus (HMPV), human bocavirus (HBoV), and human coronaviruses (HCoV) have been identified as potential respiratory pathogens (5). Adenoviruses, first isolated in the 1950s from explanted adenoid tissue, are double-stranded non-enveloped DNA viruses that naturally infect many vertebrates including human and non-human primates (6). Human adenoviruses (HAdV) are grouped into seven species of A to $G$ and to date, 56 different types (HAdV-1 to HAdV-56) have been described based on serology, whole genome sequencing, or phylogenomics (7-9). Adenovirus accounts for 5-15\% of upper and lower RTIs in infants and children hospitalized for respiratory disease $(2,10)$. Clinical signs of an AdV infection are rather nonspecific and variable and include tonsillopharyngitis, conjunctivitis, pneumonia, gastroenteritis, hepatitis, and hemorrhagic cystitis (2). Fever, pharyngitis, tonsillitis, cough, and sore throat are the most common symptoms in affected children and young adults with AdV-associated RTI (8).

\section{Objectives}

According to the importance of the main detection of exact reason of respiratory infection in human being and though the adenovirus symptoms are like other viral in-

Implication for health policy/practice/research/medical education:

With Regard to the high prevalence of respiratory infections especially Influenza worldwide, all of the attentions are focused on this viral agent. Hence, that many other agents like adenovirus, which is another important agent among respiratory acute infection, are neglected, we tried to identify this important agent beside influenza virus and other viral agents as a potential cause of respiratory infection.

Copyright (c) 2014, Pediatric Infections Research Center. This is an open-access article distributed under the terms of the Creative Commons Attribution-NonCommercial 4.0 International License (http://creativecommons.org/licenses/by-nc/4.0/) which permits copy and redistribute the material just in noncommercial usages, provided the original work is properly cited. 
fections, especially Influenza, we aimed to determine the prevalence of adenovirus infection in pediatric patients with respiratory symptoms.

\section{Patients and Methods}

\subsection{Clinical Specimens}

The specimens used in this study were from throat swabs from 328 pediatric patients with RTI admitted to the hospitals affiliated with Shiraz University of Medical Sciences from 2010 to 2012. The collected specimens were submitted to the influenza research center laboratory. The relevant clinical information was obtained through a standard questionnaire that itemized hospitalization status, age, sex, and clinical symptoms such as fever, cough, sneeze, and muscle ache. Throat swabs immersed in phosphate-buffered saline (PBS pH 7.2) and stored at $-70^{\circ} \mathrm{C}$ for subsequent DNA extraction.

\subsection{Nucleic Acid Purification and PCR Screening}

Nucleic acids from respiratory specimens were extracted using the DNA kit (AccuPrep®, Bioneer Corporation, USA) according to the manufacturer's instructions. Human adenovirus extracted DNA was detected by nestedPCR of the hexon gene as described previously (11). The first round amplification was done by the forward primer $5^{\prime}$-GCC GAG AAG GGC GTG CGC AGG T $<$ A $>-3^{\prime}$ and the reverse primer $5^{\prime}$-TAC GCC AAC TCC GCC CAC GCG C $<$ T $>$ $3^{\prime}$. The second round amplification was performed by the forward primer $5^{\prime}$-TGA CTT TTG AGG TGG ATC CAT G $<G>-3^{\prime}$ and the reverse primer $5^{-}$-GGT CTC GAT GAC GCC GCG GTG $<$ C $>-3$, both 'targeting a portion of the HAdV hexon gene including $161 \mathrm{bp}$ and $107 \mathrm{bp}$ amplicons. PCR amplication was performed using $50 \mu \mathrm{L}$ reaction volumes containing $45 \mu \mathrm{L}$ mixture containing $1 \mathrm{mM} \mathrm{Mgcl}_{2}$, $5 \mu \mathrm{L}$ PCR buffer $10 \mathrm{x}, 0.1 \mathrm{mM}$ each of deoxynucleotide triphosphate, $0.4 \mathrm{pmol} / \mu \mathrm{L}$ of each primer, $1 \mathrm{U}$ of Taq DNA polymerase, and $5 \mu \mathrm{L}$ of nucleic acid extract. The procedure included denaturation by one cycle at $94^{\circ} \mathrm{C}$ for 10 min, followed by 3 cycles at $94^{\circ} \mathrm{C}$ for $1 \mathrm{~min}, 61$ for $1 \mathrm{~min}, 72$ for 1 minute, and a final extension at $72^{\circ} \mathrm{C}$ for 10 minutes. As for the nested-PCR reaction, $5 \mu \mathrm{L}$ of the first-round PCR product was amplified as described above. PCR products were detected by $1.5 \%$ agarose gel electrophoresis followed by staining with ethidium bromide.

\section{Results}

A total of 328 throat swabs were processed and the corresponding data are shown in Table 1. Only samples from patients younger than 19 years of age were included and among them, 192 (58.54\%) and 136 (41.46\%) samples belonged to the patients younger and older than five years of age, respectively. Additionally, 150 (45.73\%) and 178 (54.27\%) samples were collected from males and females, respectively. Amongst 243 (74.08\%) patients hospitalized with ARTI, symptoms as- sociated with fever, cough, and muscle ache were seen in 238 (72.56\%), 212 (64.63\%), and 210 (64.02\%) patients, respectively (Figure 1). According to the nested-PCR results, the adenovirus was detected in 72 (21.95\%) patients; the positive results were reported in $25(34.72 \%)$ and $47(65.27 \%)$ of males' and females' samples, respectively (Figures 2 and 3 ).

Fever was seen in 70 (97.22\%) samples with positive results. Total analyzing results showed that most of the positive resulted for adenovirus were detected in samples from children older than five years of age. The majority of patients presented with upper respiratory tract symptoms including cough and muscular ache (Table 1), which are the most reported symptoms in other respiratory viral infections. According to the analysis of the results with SPSS software, we could not find any significant association between AdV positive samples and the age and gender of the patients; however, there was an association between seasons and epidemiology of the HAdV in the south region of Iran.

Table 1. Symptoms of Adenovirus Infections in Pediatric Patient

\begin{tabular}{lll}
\hline Symptom & Frequency & Present Frequency, \% \\
\hline Fever & 70 & 97.22 \\
Cough & 63 & 87.44 \\
Muscle ache & 42 & 58.30 \\
\hline
\end{tabular}

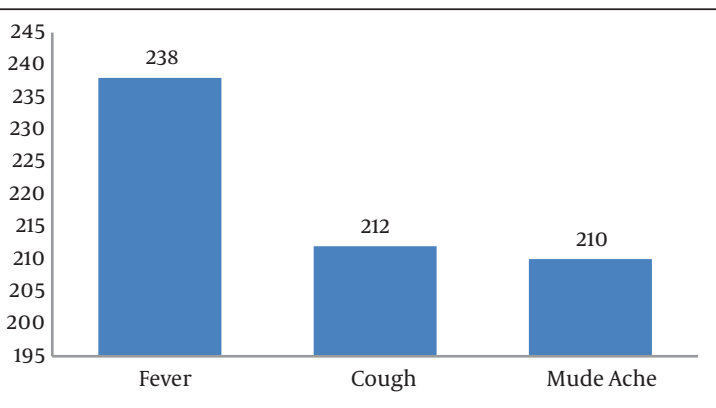

Figure 1. Symptoms of Acute Respiratory Infection in Participants

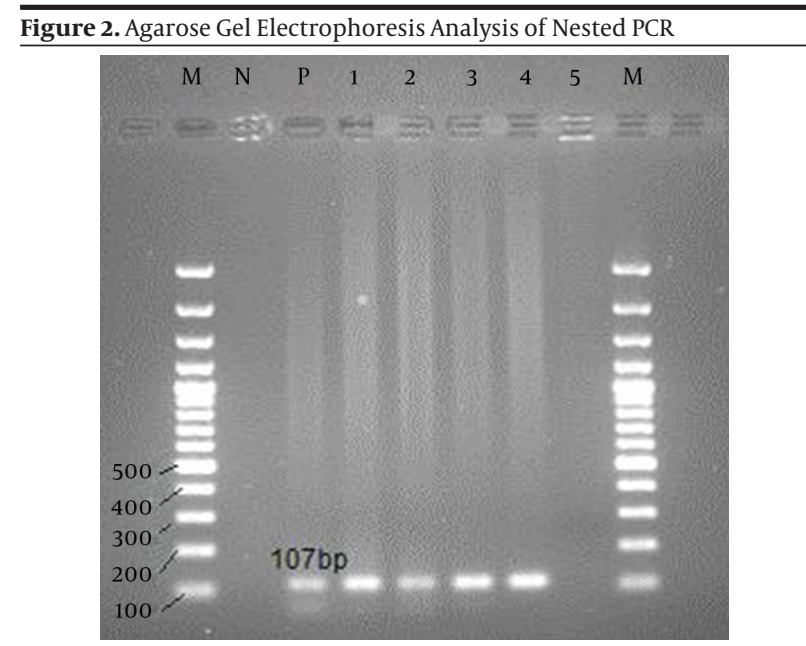

M: DNA molecular marker, N: negative control, P: positive Control, 5: negative cases, 1-4: positive cases. 


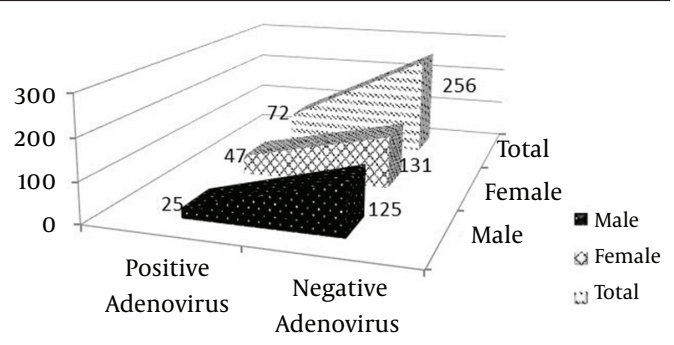

\begin{tabular}{l|c|c}
\cline { 2 - 3 } \multicolumn{1}{c|}{} & positive Adenovirus & negative Adenovirus \\
\hline Male & 25 & 125 \\
\hline WFemale & 47 & 131 \\
\hline WTotal & 72 & 256 \\
\hline
\end{tabular}

Figure 3. Frequency of Negative and Positive Results of Adenovirus Samples in Different Genders

\section{Discussion}

Respiratory infection is a leading cause of morbidity, hospitalization, and death in pediatric patients (12). Approximately $80 \%$ of upper RTIs have viral etiology and can lead to asthma exacerbation and acute otitis media (13). Additionally, lower RTIs are manifested as bronchitis, bronchiolitis, and pneumonia (14). Adenoviruses are most important respiratory pathogens, and constitute $5-8 \%$ of all RTIs in infants and children younger than two years of age. HAdV infections are clinically similar to those of other respiratory viruses and the definitive determination of viral type and rapid diagnosis is problematic and cannot be achieved on the clinical ground. Due to the persistence and prolonged shedding of adenovirus, diagnostic approaches must be sufficiently sensitive to detect low levels of virus in clinical specimens. Adenovirus infections can be diagnosed by a variety of traditional and molecular methods. Molecular methods are most sensitive for detecting adenovirus in clinical specimens. The present study was conducted to detect HAdV by nested PCR. The frequency of HAdV in our study was $22 \%$ (72 out of 328 samples) that is slightly higher than the frequency of $14.4 \%$ reported by another study from Iran $(15,16)$, and several parts of the world including Oman (15\%), Kenya (14\%), Brazil (10\%), Korea (10.3\%), Australia (7.3\%), Hung Kong (5.3\%), Mejia (5.2\%), and China (4.9\%) (11,17-22). According to these studies, HAdV is widespread throughout the world and is one of the causative agents of upper and lower RTIs in pediatrics. Amongst 72 cases with HAdV infections, 25 patients were males and 47 females. In contrary to other reports, female patients composed a higher proportion in our study $(1,2,11,18,23)$.

Similar studies conducted by Arabzadeh et al. in Iran (24) and by Zou et al. in China showed no significant differences in the prevalence of HAdV infections between males and females. Adenovirus diseases usually result from reinfection and the elderly often have partial immunity due to pre-existing systemic and mucosal antibodies (25). In addition, elderly might have lesser amount of respiratory secretions and lower viral load in compari- son to the children. Nearly $74 \%$ of children infected with HAdV were older than five years of age. However, other reports showed that HAdV mostly occur in children younger than two years of age, which is not in agreement with similar investigations conducted by Saffar et al. $(2,23,26)$, Naghipour et al. and other reports across the world (27).

HAdV infections showed a variety of clinical symptoms. Most common symptoms observed in our study of 72 children with HAdV infections without co-infection were cough (64.63\%), fever (72.56\%), and muscular ache (64.02\%). There is no specific symptom associated with HAdV infection and HAdV infected children reported by Shike et al. and Kahbazi et al. (16) exhibited non-specific symptoms such as fever and cough (10). The results of this study showed that acute respiratory adenovirus infection in Shiraz occurred mostly during months of November 2011 to February 2012. In contrast to other studies, HAdV was more prevalent in children older than five years of age. Additionally, the infection rate in females was higher than in males.

\section{Acknowledgements}

We appreciate professor Kadivar for supporting our study in sampling.

\section{Authors' Contribution}

All of the authors have been contributed in different parts of the study and help in writing the article.

\section{Financial Disclosure}

There is no conflict of interest.

\section{Funding/Support}

This study was supported by Shiraz University of Medical Sciences. There wasn't any sponsor for this study.

\section{References}

1. Kalu SU, Loeffelholz M, Beck E, Patel JA, Revai K, Fan J, et al. Persistence of adenovirus nucleic acids in nasopharyngeal secretions: a diagnostic conundrum. Pediatr Infect Dis J. 2010;29(8):746-50.

2. Marinheiro JC, Sanalios RB, Santos DC, Costa CA, Harsi CM. Duplex-PCR assay for the detection of adenovirus and respiratory syncytial virus in nasopharyngeal samples. Mem Inst Oswaldo Cruz. 2009;104(1):118-20.

3. Abd-Jamil J, Teoh BT, Hassan EH, Roslan N, Abubakar S. Molecular identification of adenovirus causing respiratory tract infection in pediatric patients at the University of Malaya Medical Center. BMC Pediatr. 2010;10:46

4. Dominguez SR, Robinson CC, Holmes KV. Detection of four human coronaviruses in respiratory infections in children: a oneyear study in Colorado. J Med Virol. 2009;81(9):1597-604.

5. Albuquerque MC, Pena GP, Varella RB, Gallucci G, Erdman D, Santos N. Novel respiratory virus infections in children, Brazil. Emerg Infect Dis. 2009;15(5):806-8.

6. Chen EC, Yagi S, Kelly KR, Mendoza SP, Tarara RP, Canfield DR, et al. Cross-species transmission of a novel adenovirus associated with a fulminant pneumonia outbreak in a new world monkey colony. PLoS Pathog. 2011;7(8):10.

7. Luiz LN, Leite JP, Yokosawa J, Carneiro BM, Pereira Filho E, Oliveira 
TF, et al. Molecular characterization of adenoviruses from children presenting with acute respiratory disease in Uberlandia, Minas Gerais, Brazil, and detection of an isolate genetically related to feline adenovirus. Mem Inst Oswaldo Cruz. 2010;105(5):712-6.

8. Lynch JP, 3rd, Fishbein M, Echavarria M. Adenovirus. Semin Respir Crit Care Med. 2011;32(4):494-511.

9. Espinola EE, Russomando G, Basualdo W, Benitez DA, Meza G, Maldonado L, et al. Genetic diversity of human adenovirus in hospitalized children with severe acute lower respiratory infections in Paraguay. J Clin Virol. 2012;53(4):367-9.

10. Shike H, Shimizu C, Kanegaye J, Foley JL, Burns JC. Quantitation of adenovirus genome during acute infection in normal children. Pediatr Infect Dis J. 2005;24(1):29-33.

11. Ou ZY, Zeng QY, Wang FH, Xia HM, Lu JP, Xia JQ, et al. Retrospective study of adenovirus in autopsied pulmonary tissue of pediatric fatal pneumonia in South China. BMC Infect Dis. 2008;8:122.

12. Hadi N, Kashef S, Moazzen M, Pour MS, Rezaei N. Survey of Mycoplasma pneumoniae in Iranian children with acute lower respiratory tract infections. Braz J Infect Dis. 2011;15(2):97-101.

13. Mahony JB. Detection of respiratory viruses by molecular methods. Clin Microbiol Rev. 2008;21(4):716-47.

14. Tregoning JS, Schwarze J. Respiratory viral infections in infants: causes, clinical symptoms, virology, and immunology. Clin Microbiol Rev. 2010;23(1):74-98.

15. Malekshahi SS, Azad TM, Yavarian J, Shahmahmoodi S, Naseri M Rezaei F. Molecular detection of respiratory viruses in clinical specimens from children with acute respiratory disease in Iran. Pediatr Infect Dis J. 2010;29(10):931-3.

16. Kahbazi M, Fahmizad A, Armin S, Ghanaee RM, Fallah F, Shiva F, et al. Aetiology of upper respiratory tract infections in children in Arak city: a community based study. Acta Microbiol Immunol Hung. 2011;58(4):289-96.

17. Yeung R, Eshaghi A, Lombos E, Blair J, Mazzulli T, Burton L, et al Characterization of culture-positive adenovirus serotypes from respiratory specimens in Toronto, Ontario, Canada: September 2007-June 2008. Virol J. 2009;6(11):1-3.
18. Ahmed JA, Katz MA, Auko E, Njenga MK, Weinberg M, Kapella BK, et al. Epidemiology of respiratory viral infections in two longterm refugee camps in Kenya, 2007-2010. BMC Infect Dis. 2012;12:7.

19. Choi EH, Lee HJ, Kim SJ, Eun BW, Kim NH, Lee JA, et al. The association of newly identified respiratory viruses with lower respiratory tract infections in Korean children, 2000-2005. Clin Infect Dis. 2006;43(5):585-92.

20. Callaway Z, Kim SH, Kim JY, Kim DW, Kim CK. Adenovirus infection with serious pulmonary sequelae in Korean children. Clin Respir J. 2011;5(2):92-8.

21. Sloots TP, McErlean P, Speicher DJ, Arden KE, Nissen MD, Mackay IM. Evidence of human coronavirus HKU1 and human bocavirus in Australian children. J Clin Virol. 2006;35(1):99-102.

22. Zhang HY, Li ZM, Zhang GL, Diao TT, Cao CX, Sun HQ. Respiratory viruses in hospitalized children with acute lower respiratory tract infections in harbin, China.Jpn J Infect Dis. 2009;62(6):458-60.

23. Stroparo E, Cruz CR, Debur Mdo C, Vidal LR, Nogueira MB, Almeida SM, et al. Adenovirus respiratory infection: significant increase in diagnosis using PCR comparing with antigen detection and culture methods. Rev Inst Med Trop Sao Paulo. 2010;52(6):317-21.

24. Arabzadeh S, Parizi M, Molaie H, Afshar A, Salari A. Evaluate the prevalence of Parainfluenza, Adenovirus \& respiratory Syncytial Virus with multiplex PCR in children referees to teaching hospitals with bronchiolitis symptoms. Kerman Univ Med Sci. 2008;15(4):305-11.

25. Zou L, Zhou J, Li H, Wu J, Mo Y, Chen Q, et al. Human adenovirus infection in children with acute respiratory tract disease in Guangzhou, China. APMIS. 2012;120(8):683-8.

26. Saffar MJ, Naghshvar F, Alaee E. Role of respiratory syncytial and Influenza viruses in acute lower respiratory tract infections in mazandaranian children in 2002. J Mazandaran Univ Med Sci. 2002;12(37):20-9.

27. Naghipour M, Hart CA, Dove W, Leatherbarrow AJ, Cuevas LE. Adenovirus infections within a family cohort in Iran. Pediatr Pulmonol. 2009;44(8):749-53. 